http://dx.doi.org/10.30681/23588403v11i0194106

\title{
A RELAÇÃO ENTRE MULTIMODALIDADE E A PROPOSTA DE MULTILETRAMENTOS COM A CARTILHA CAMINHO SUAVE
}

Data de recebimento: 19/10/2017

Aceite: 12/12/2017

Maria Elisabeth Barbosa ROSAL (UNICSUL) ${ }^{1}$

\begin{abstract}
Resumo: Os textos multimodais são multissemióticos e permitem uma grande quantidade de estímulos sensoriais e visuais. Como qualquer texto, estão vinculados a contextos socioculturais e históricos específicos que o pesquisador, os autores de recursos didáticos e a escola não podem perder de vista, conforme Kress e Van Leeuwen (1996; 2002), Van Leeuwen (2011) e Mayer (2009). Também deve ser considerada a relação entre multimodalidade e leitura proposta por Dionísio $(2005 ; 2011 ; 2014)$. Para tratar de múltiplos aspectos no ambiente escolar surge o campo de pesquisa da Pedagogia de Multiletramentos, mostrando que a diversidade não é apenas de linguagens, mas de contextos de produção e circulação dos textos, envolvendo a Pedagogia de Multiletramentos proposta pelo Grupo de Nova Londres (2000) como também Rojo (2009; 2012). Com esses pressupostos, o presente artigo toma como objeto de análise a capa da $132^{a}$ edição de 2015 da cartilha Caminho Suave, de Branca Alves de Lima, e mostra que suas escolhas semióticas, marcadas por uma ideologia conservadora, possibilitam multiletramentos espontâneos que acontecerão à medida que os alunos interligam os conhecimentos a diferentes significados e interpretações dos diferentes modos (texto e imagem) e recursos semióticos.
\end{abstract}

Palavras-chave: Multimodalidade. Multiletramentos. Caminho Suave. Ideologia.

\begin{abstract}
The multimodal texts are multisemiotic, allowing a great amount of sensorial and visual stimuli. They are also linked to specific sociocultural and historical contexts that the researcher, resource writers and school can not lose sight of, according to Van Leeuwen (2011) and Mayer (2009). The relationship between multimodality and reading proposed by Dionísio (2005, 2011, 2014) should also be considered. In order to deal with multiple aspects in the school environment, the field of research of Pedagogy of Multiliteracy arises, showing that the diversity is not only of languages, but of production contexts and text circulation, involving the Multilevel Pedagogy proposed by the New London Group (2000) as well as Red $(2009 ; 2012)$. With these assumptions, the present article analyzes the cover of the 132nd edition of 2015 from the booklet "Caminho Suave", by Branca Alves de Lima, and shows that its semiotic choices, marked by a conservative ideology, allow for spontaneous multiliteracy that measures how students interconnect knowledge to different meanings and interpretations of the different modes (text and image) and semiotic resources.
\end{abstract}

Keywords: Multimodality. Multiliteracy. Caminho Suave. Ideology.

\footnotetext{
${ }^{1}$ Mestranda em Linguística na Universidade Cruzeiro do Sul - UNICSUL; Pedagoga pela Universidade Bandeirante de São Paulo - UNIBAN, São Paulo, Brasil.

Contato: elisa.bethsp9@gmail.com
} 


\section{Considerações iniciais}

A pluralidade e a variedade dos modos de comunicação e informação chamaram a atenção de inúmeros pesquisadores provenientes de uma vasta quantidade de esferas do conhecimento e campos de estudo - Análise Crítica do Discurso, Análise do Discurso de Linha Francesa, Linguística Aplicada, Semiótica, Semiótica Social, Pedagogia, Psicologia, dentre outras áreas - quanto aos novos materiais didáticos, ou seja, quanto à multimodalidade. A propagação dos textos multimodais e a introdução dos recursos midiáticos e tecnológicos envolvendo essas diversas linguagens já circulam nas escolas, exigindo novas práticas pedagógicas que levem em conta a articulação entre a linguagem verbal e a não verbal para a criação de sentidos (JEWITT, 2002; 2005; 2009).

O conceito de multimodalidade torna-se essencial para compreender não só como se articulam, mas para interpretar os sentidos sociais construídos por esses textos (CABRAL, 2013). A sua aplicabilidade e expansão nos estudos da linguagem, segundo os linguistas e semioticistas sociais Kress (2000; 2001), Jewitt e Kress (2003) e Van Leeuwen (2011) sugerem a necessidade de produzir estratégias de análise para verificar e entender como funciona e o significado de cada um dos seus recursos semióticos presentes em um texto. Também é necessário entender como constroem, de maneira conjunta, diferentes significados e interpretações dos modais (texto e imagem) e recursos semióticos (cores, tipografia e outros elementos). Os dois pesquisadores publicaram em conjunto a obra Reading Images: a grammar of visual designer (1996) abordando a Gramática do Design Visual (GDV) e propondo descrever como ocorre a significação e a interação pela qual pessoas, coisas e lugares são combinados em uma totalidade constitutiva de sentido, causam implicações diversas ao significar o uso integrado de diferentes recursos, que podem ser expressos por meio de escolhas que envolvem uma complexa inter-relação entre texto escrito, imagens e outros elementos gráficos e multimídia. Juntos, tais elementos constituem um design visual a partir da combinação de vários modos: visual, textual, gestual, auditivo, movimento e efeitos de som.

São modos que podem ser descritos como o efeito de uma ação cultural para modelar algum material, transformando-o em recursos para representação, a fim de impor interesses, expressar necessidades e valores sociais individuais, Kress \& Van Leeuwen (1996) pontuam que a avaliação atribuída às representações visuais pode ser feita com base em seis marcadores que dão sentido às imagens e formam amplas e complexas estruturas visuais: a cor, a contextualização, a representação, a profundidade, a iluminação e o brilho; tais elementos 
trazem à tona efeitos e transformações que auxiliam na própria compreensão do texto, pois lançam mão de multisemioses, ou seja, há combinação de cores, o modo como ocorrem destaques das imagens, representações de objetos ou pessoas e diagramação de elementos que podem estar contribuindo para o significado do texto e determinando o que se evidencia e condiciona a leitura do leitor (KRESS \& VAN LEEUWEN, 2002).

Dionísio (2005) aponta que nossa sociedade está cada vez mais visual: é com muita facilidade que se criam novas imagens, novos layouts, bem como se divulgam tais criações para uma ampla audiência (p.159). Tal fato interfere com o texto escrito, que apresenta cada vez mais relação com a imagem. Assim, o sujeito letrado deve ser capaz de interpretar e produzir mensagens compostas por diferentes signos e, na "sociedade contemporânea, a prática de letramento da escrita, do signo verbal deve ser incorporada à prática de letramento da imagem, do signo visual" (DIONÍSIO, 2005, p. 160). O sujeito letrado deve ter, então, as ferramentas necessárias à produção e compreensão dos textos multimodais para levar em conta os variados usos da linguagem, analisar a correlação entre texto escrito, imagens e outros elementos gráficos, além de compreender os sentidos sociais construídos por esses textos.

$\mathrm{Na}$ concepção linguística, o conceito de letramento é usado para a aprendizagem de leitura e escrita de diferentes gêneros textuais, conforme as especificidades da cultura e do contexto histórico. O termo multiletramento surge para apontar não só a diversidade das práticas letradas, mas a " multiplicidade cultural das populações, da produção e circulação dos textos e da constituição semiótica pela qual ela se informa e se comunica" (ROJO e ALMEIDA, 2012, pp.12-13). Na fase inicial de escolarização, intensifica-se o processo de criar situações diversificadas para a leitura e a escrita, motivando o desenvolvimento de capacidades relativas à compreensão, à produção de sentido para a formação cidadã e plural dos alunos.

O presente artigo propõe a capa da cartilha Caminho Suave como objeto de análise para demonstrar a aplicabilidade da multimodalidade e multiletramento através da sua composição, cores e tipografia. Esse corpus será abordado segundo a Teoria da Multimodalidade e na Gramática do Design Visual de Kress e Van Leeuwen (1996; 2002), Van Leewen (2011), e Mayer (2009), e na relação entre multimodalidade e leitura proposta por Dionísio $(2005 ; 2011 ; 2014)$. Para tratar de múltiplos aspectos no ambiente escolar surge o campo de pesquisa da Pedagogia de Multiletramentos, que mostra que a diversidade não é apenas de linguagens, mas de contextos de produção e circulação dos textos. Ela envolve a Pedagogia de Multiletramentos proposta pelo Grupo de Nova Londres (2000), como também de Rojo (2009, 2012) e de Rojo e Almeida (2012). 
A cartilha Caminho Suave passou por modificações e inovações desde 1948, quando foi lançada por Branca Alves de Lima, e ainda hoje é uma aliada para a alfabetização e letramento. Suas lições mostram que a linguagem visual oferece muitas possibilidades de investigação em sua materialidade (ilustrações, disposição das lições e exercícios, tipos de letra, cor etc.), o que evidencia a necessidade de letramentos de diversas naturezas.

Conforme o Centro de Referência em Educação Mário Covas, calcula-se que do ano de 1948 até meados da década de 1990 foram vendidos 40 milhões de exemplares dessa cartilha. Daí decorre a importância e motivação para esse estudo: analisar a composição multimodal da capa, em sua $132^{\text {a }}$ edição de 2015 , na qual propõe uma leitura múltipla, pelo diálogo entre as imagens, palavras e imagem-palavra e perceber como essas mudanças são importantes ou não para os autores de recursos didáticos voltados à alfabetização.

O livro Reading Images: a grammar of visual designer - Gramática do Design Visual de Kress e van Leeuwen (1996), é uma resposta à necessidade de desenvolver métodos de análise textual que contemplem as imagens. Seu objetivo é analisar como as principais estruturas composicionais são usadas pelos produtores de imagem contemporâneos para produzir sentido. Segundo Kress e Van Leeuwen (2002) as imagens estão além de apenas reproduzir a realidade, elas "produzem imagens da realidade" e, nesse sentido, não devem ser vistas apenas como meio para construir um conhecimento sobre fatos de uma cultura, mas como construções históricas e culturais. A linguagem visual é "culturalmente definida" e, apesar da crença generalizada, não é "universal e transparente” (KRESS e VAN LEEUWEN, 2002, p. 4).

\section{Multimodalidade, Letramento e Multiletramentos}

Com o desenvolvimento tecnológico, o fenômeno da globalização e a diversidade cultural e social, os textos estão cada vez mais multimodais. Seus sentidos são resultantes da relação textual estabelecida a partir dos diferentes modos utilizados na sua constituição e dos elementos presentes, tanto no nível verbal quanto no imagético. Kress e Van Leeuwen definem multimodalidade como:

[...] o uso de vários modos semióticos no design de um produto semiótico ou evento, juntamente com a maneira particular em que estes modos são combinados - eles podem, por exemplo, reforçar-se mutuamente (dizer a 
mesma coisa de formas diferentes), desempenhar papéis complementares.

(KRESS E VAN LEEUWEN, 2002, p. 20)

O conceito de letramento é abordado por Soares como "[...] é não só aquele que sabe ler e escrever, mas aquele que usa socialmente a leitura e a escrita, pratica a leitura e a escrita, responde adequadamente às demandas sociais de leitura e de escrita (SOARES, 2012, pp. 3940)". Ou seja, na leitura ocorre mudança, fazendo com que a relação do aluno com seus aspectos psíquicos, cultural, político, cognitivo, linguístico e econômico seja alterada. O letramento, portanto, é fator de mudança social. Tornar-se letrado(a) é transformar-se, é criar condições para o aluno viver e participar das práticas sociais da contemporaneidade.

Os modos discursivos da sociedade contemporânea têm multiplicidade de linguagens, de mídias, de cultura e exigem novas práticas e o ensino com mais sentido para o aluno. Logo, nesse novo cenário educacional, o aluno precisa dominar novos modos de escrever e ler além dos modelos já tradicionais. Esse novo aluno precisa fazer a construção de sentidos pela composição das múltiplas linguagens e compreender que os elementos visuais presentes não são apenas ilustrações, mas compõem o texto, e deles depende a compreensão textual.

Levando em consideração os novos letramentos advindos da sociedade contemporânea o termo multiletramentos surgiu como proposta didática transformadora, tem o intuito de englobar discussões referentes às novas pedagogias do letramento e pensar sobre os processos de construção de significados, fundamental para a inserção de um currículo responsivo no mundo contemporâneo. Essa nova abordagem, criada por um grupo de pesquisadores australianos, americanos e ingleses denominados The New London Group (NLG) ou Grupo de Nova Londres (GNL) visa tornar o ensino em sala de aula mais inclusivo de diversidade cultural, linguística, comunicativa e tecnológica, decorrentes dos efeitos da globalização, característicos das formas contemporâneas de produção de sentido.

Com a publicação do artigo A Pedagogy of Mutliliteracies: Designing Social Future (2000), o Grupo de Nova Londres aponta uma análise da conjuntura por meio da semiótica social. Distingue dois lados específicos e fundamentais presentes nas sociedades contemporâneas, sobretudo nas urbanas: a multiplicidade cultural e semiótica na constituição dos textos pelos quais ela se informa e se comunica. Segundo Pinheiro, O NLG ${ }^{2}$ defende um

\footnotetext{
${ }^{2}$ O NLG era composto pelos seguintes membros: Allan Luke, William Cope, Carmen Luke, Courtney Cazden, Charles Eliot, Gunther Kress, Jim Gee, Martin Nakata, Mary Kalantzis, Norman Fairclough e Sarah Michaels.
} 
ensino que busque compreender e considerar essa diversidade e deem visibilidade às dimensões profissional, pessoal e de participação cívica:

(...) o grupo propôs um conceito-chave da pedagogia dos multiletramentos: o design - uma (re)apropriação do termo "design" da dimensão profissional (mundo do trabalho) para as outras duas dimensões da vida social (pessoal e de participação cívica), na tentativa de colocá-las também sob escrutínio de interpretações e ressignificações possíveis em diferentes contextos, tornandoas suscetíveis ao dinamismo, interesse pessoal e capacidade de transformação. (2016, p.526)

Para referir-se à maneira como os indivíduos utilizam os recursos de significação disponíveis em um determinado contexto (tempo e lugar), a fim de alcançar os seus objetivos e também para desenvolver um eixo estruturador num currículo escolar, o grupo concebeu o termo design, que representa a construção de sentidos na língua, na linguagem e na aprendizagem. Quem constrói os sentidos é o sujeito, o agente ou designer de sentidos, e não um simples receptor deles.

A Pedagogia de Multiletramentos proposta pelo Grupo de Nova Londres (2000) é voltada a um currículo responsivo social e cultural, ampliou a visão de letramento e propiciou que as práticas sociais de leitura e escrita fossem contextualizadas de acordo com a realidade, transformando os alunos em criadores de sentidos de textos multissemióticos impressos ou digitais (ROJO e ALMEIDA, 2012, p. 19). Segundo Rojo (2009) o letramento é exigido "pelos textos contemporâneos, ampliando a noção de letramentos para o campo da imagem, da música, das outras semioses que não somente a escrita" (p. 107).

A necessidade de a escola estar preparada para os multiletramentos se estende, obviamente, aos seus materiais. Eles devem fazer uma abordagem contextualizada e adequada da pluralidade semiótica e social, sem enfatizar apenas um tipo de linguagem ou grupo social.

\section{Análise da capa da cartilha Caminho Suave}

A capa da cartilha Caminho suave passou por algumas modificações ao longo dos anos, sendo que em sua versão atual apresenta a composição que pode ser vista na Figura 1. 
Figura 1 - Capa da 132a edição (2015) da cartilha Caminho Suave.

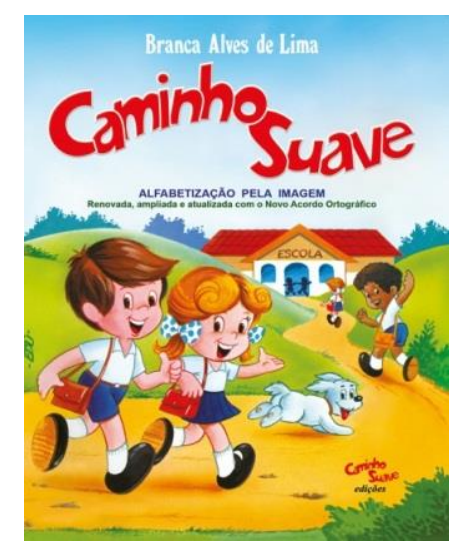

$\mathrm{Na}$ imagem da capa é possível observar as cores utilizadas e a tipografia, apontadas como importantes fontes de significados. Para oferecer uma visão mais ampla, aplica-se a proposta de análise de textos multimodais de Kress \& Van Leeuwen (1996) ajustadas segundo a Gramática Sistêmica Funcional hallidayana (Halliday, 1985). A Gramática Visual busca descrever a maneira pela qual os elementos retratados - pessoas, lugares e coisas - se combinam em "enunciados" visuais de maior ou menor complexidade e extensão.

Kress e Van Leeuwen (1996) nomeiam as categorias analíticas de metafunções: representacional, interativa e composicional. Para esses autores a função representacional descreverá os participantes quanto à ação que desenvolvem em uma imagem - seres, objetos e lugares; a função interativa descreverá as relações sociointerativas construídas por meio da imagem - autora, leitor e o objeto; e a função composicional constituirá a estrutura organização dos elementos na imagem - com o contexto em e para o qual eles foram produzidos: coerência e coesão. Essa função composicional que estrutura e organiza um texto, nessa análise, segundo Kress e van Leuwen (1996) compreende três princípios que relacionam essa composição por meio de três sistemas de um texto: o valor informativo (o posicionamento dos elementos dentro da composição visual da capa como direita, esquerda, centro, etc., nesse caso, induz o leitor na parte superior a ler o nome dessa cartilha); saliência (os elementos presentes estão conectados e o destaque é para o par de crianças brancas e o nome, Caminho Suave); e enquadramento/estrutura (os personagens e elementos da imagem, no plano amplo, fazem o leitor perceber que a escola é um lugar feliz). 
Essa integração permite que imagem e texto assumam funções diferentes para a atribuição de significados, não significando uma mera substituição de um recurso por outro, mas, considerando as relações; tudo dependerá do leitor que fará a articulação e interpretação dos diversos modos que compõem o texto, para produzir sentido em um texto multimodal.

\section{Multimodalidade da cartilha}

A pesquisa bibliográfica indica que Kress e Van Leeuwen (1996) e Dionísio (2005; 2011) entendem que há uma harmonia entre textos verbais e não verbais, apresentando crescente combinação entre o visual e o verbal. Dionísio (2005, p.159) destaca que "imagem e palavra mantêm uma relação cada vez mais próxima, cada vez mais integrada”, e a materialidade da cartilha é facilmente compreendida ao articular elementos tipográficos e imagéticos (ilustrações). Esses recursos presentes nos variados textos através dos modos de representação produzem determinados efeitos de sentidos em sua construção textual. É essa junção que torna o texto multimodal ou multissemiótico conforme entendido por Dionísio (2014).

Ao analisar os recursos multimodais na capa da cartilha constata-se, na sua composição visual, a presença de vários elementos representacionais (composição espacial, cores variadas, tipos diferentes de fontes das letras e tamanhos, presença de objetos, coisas, animal e pessoas).

Em termos de cores, as análises levam em conta as categorias formuladas por Kress \& Van Leeuwen (2002). A escala de pureza das cores dessa capa se realiza desde o alto grau de luminosidade do amarelo da estrada até o vermelho do título. Os tons variados de azul do céu levam em conta a harmonia da escala de saturação e formam um continuum de intensidade máxima do sentimento ou emoção até a sua diluição máxima, em que sentimentos e emoções são neutralizados, levando as crianças a buscarem dentro da escola o conhecimento tradicional da escolarização. Essa relação de cores (quente-frio) pode estar indicando valores construídos em cada cultura associados à essência dos objetos e à identidade individual significativamente demarcada. Essa escola, em decorrência da estrutura simples e bonita, cativa a criança, o que fica claro no convite das formas de suas letras que sugerem um ensino e aprendizagem prazerosos e não lineares, é flexível e assegura ao aluno que seu tempo de aprender a aprender será respeitado. 
Observa-se que há também fenômenos extralinguísticos significativos nessa capa, seja pela leitura dos gestos dos personagens ou pela apresentação tipográfica das letras em diferentes fontes, que se sobrepõe e estão dispostas em curva; de modo lúdico, assumem uma função poética e apresentam uma sutil conexão de harmonia estabelecida entre a linguagem verbal e não verbal.

Constata-se num primeiro plano que os recursos de "saliência" operam no sentido de atrair a atenção do leitor: a capa mostra um par de crianças brancas no caminho para a escola que aparece ao fundo, ambos situados como elementos principais, com maior valor de informação para análise.

De acordo com a abordagem multimodal as análises dessa capa constroem significados para além da escrita; podem ainda ser explorados outros aspectos, como definir identidade social dos leitores, a sua evolução histórica e estética, e o tipo de escola na qual estão inseridos. Portanto, os elementos analisados que compõe essa capa (como quaisquer outros textos) estão vinculados a contextos socioculturais e históricos específicos que o pesquisador, os autores de recursos didáticos e a escola não podem perder de vista (KRESS e VAN LEEUWEN, 1996; 2001) e devem considerar como recursos importantes para captar a representação da sociedade atual, do contexto escolar e familiar.

\section{Multiletramentos na capa}

Segundo a Pedagogia de Multiletramentos, a capa da cartilha oferece elementos para o aluno construir significados pela composição das múltiplas linguagens presentes, tanto nas imagens que dialogam sobre chegar à escola, como na diagramação do título que embala tranquilidade e alegria para seu dia na escola. Os elementos visuais estimularão a competência leitora e a compreensão de que, direta ou indiretamente, a alegria de ir à escola será incorporada à sua rotina.

Numa perspectiva comunicativa e potencializadora para criação de significados, as imagens tomam parte da composição dos sentidos que a cartilha transmite "os multiletramentos levam em conta a multimodalidade (linguística, visual, gestual, espacial e auditiva) e a multiplicidade de significações e contextos/culturas" (ROJO, 2012, p.38); é possível apontar informações sobre os elementos que aparecem na imagem e são importantes para a familiarização nessa fase inicial de alfabetização. A fim de posicioná-los como cidadãos 
participantes e ativos nesse processo inicial de ensino aprendizagem, pode-se incentivar a investigação de representação entre a linguagem visual e a verbal. Identificar cores, letras, palavras, quantidade de pessoas, objetos, animais e a paisagem desse cenário até entrar na escola proporcionará a interação entre os participantes e a construção para a formação e constituição do aluno-leitor.

Ao mostrar o caminho e nome do título da cartilha também em uma percepção de movimento como uma onda suave, a escola ao fundo com todos os personagens percorrendo o caminho sorrindo (inclusive o pequeno cachorro) pode-se explorar sentimentos, afetividade, sensações e desenvolver as potencialidades discursivas dos alunos, o respeito às opiniões dos colegas. Através de tais explorações os resultados, certamente, serão significativos.

Como ensinam Kress e van Leeuwem, os textos multimodais precisam ser analisados em sua complexidade semiótica e social. A teoria dos multiletramentos mostra que a escola deve contemplar a diversidade de textos e linguagens, bem como seus contextos de produção e circulação.

\section{Conclusão}

Atualmente, os textos têm recursos gráficos e imagens colocando em cena o conceito de texto multimodal, isto é, textos compostos por mais de um código semiótico (KRESS; VAN LEEUWEN, 1996). Este tipo de texto ocorre quando os gêneros escritos combinam a língua, a imagem e as características gráficas (cores, formas, sombras, etc.) em elementos representativos que contribuem para significar o texto como um todo e alicerçar a compreensão da multimodalidade.

As escolhas dos componentes visuais e linguísticos na capa da cartilha se complementam e trazem um complexo de significação pertencente a um contexto sócio histórico bem definido. O equilíbrio estabelecido pela presença de cores com temperaturas frias e quentes transmite ideias básicas simplificadas, nas quais a imagem se materializa em diferentes signos produtores de uma "imagem da realidade" e demonstram regularidades culturalmente produzidas no processo de construção de significados (Kress e van Leeuwen, 1996; 2006).

A cartilha Caminho Suave, como qualquer outro texto multimodal, está sujeita aos fatores extralinguísticos apresentados nesta análise. As imagens da capa produzem um sentido 
de harmonia social e racial que apaga outros sentidos. É uma ideologia conservadora que é reproduzida mesmo sem consciência ou motivação explícita dos autores e ilustradores. E a cartilha revela essa ideologia ao tornar as crianças brancas e loiras protagonistas da capa e de todo seu conteúdo.

A cartilha possibilita multiletramentos espontâneos, que acontecerão à medida que os alunos interliguem os conhecimentos proporcionados pelas leituras provenientes da linguagem visual e, ao levar em conta a multimodalidade e a multiplicidade de significações e contextos, o processo de ensino aprendizagem da leitura e escrita se efetivará.

Mesmo que a criança não tenha conhecimento e consciência da metalinguagem da Gramática do Design Visual, com a mediação do professor e por meio das perspectivas multimodais, esse processo inicial de escolarização será mais atrativo e as análises desenvolverão habilidades interpretativas do aluno; além de proporcionar oportunidades de práticas de (multi)letramento, o ensino com os textos multimodais despertará o interesse das crianças.

Até mesmo a escolha da frase na parte inferior (alfabetização pela imagem) complementa o convite para promover novas práticas: a cartilha oferece limitações, mas ensina como o professor deve trilhar seu trabalho nas situações de aprendizagem que envolve as linguagens oral e escrita nessa etapa educativa, com o objetivo de multiletramento, a GDV contribui para a construção de sentidos ao evidenciar o caráter indissociável entre texto e imagem nessa capa.

\section{REFERÊNCIAS}

BUZEN, C.; MENDONÇA, M. Múltiplas linguagens para o ensino médio. São Paulo: Parábola Editorial, 2011.

CABRAL, A.L.T. Leitura de Textos Multimodais: simultaneidade e integração na construção de sentidos. Intersecções, v. 6, n. 2, 2013. Disponível em: $<$ http://www.portal.anchieta.br/revistas-e-

livros/interseccoes/pdf/interseccoes_ano_6_numero_2.pdf>. Acesso em: 26 abr 2017.

COPE, B.; KALANTZIS, M. (Ed.). Multiliteracies: literacy learning and the design of social

futures. Routledge: Psychology Press, 2000. 
DIONÍSIO, A.P. Gêneros multimodais e multiletramento. In: KARWOSKI, A. M. GAYDECZKA, B. BRITO, K. S. (org.). Gêneros textuais: Reflexão e Ensino. Palmas e União da Vitória: Kaygangue, 2005.

Multimodalidades e leituras: funcionamento cognitivo, recursos semióticos e convenções visuais. Recife: Pipas Comunicação, 2014.

Multimodalidade, gênero textual e leitura. In: BUZEN, C.; MENDONÇA, M. Múltiplas linguagens para o ensino médio. São Paulo: Parábola Editorial, 2011.

GRUPO DE NOVA LONDRES (NEW LONDON GROUP). A Pedagogy of Multiliteracies: Designing Social Futures. In COPE, B.; KALANTZIS, M. (Ed.). Multiliteracies: literacy learning and the design of social futures. Routledge: Psychology Press, 2000, p. 9-37.

HALLIDAY, M.A.K. An introduction to functional grammar. Baltimore: Edward Arnold, 1985 .

JEWITT, C. The move from page to screen: the multimodal reshaping of school English. Visual Communication, v. 1, n. 2, 2002, p. 171-96.

Multimodal reading and writing on screen. Discourse: Studies in the Cultural Politics of Education, v. 26, n. 3, 2005, p. 315-32.

. The Routledge Handbook of Multimodal Analysis. London: Routledge, 2009.

JEWITT, C., KRESS, G. Multimodal Literacy. New York: Peter Lang, 2003.

KARWOSKI, A. M. GAYDECZKA, B. BRITO, K. S. (org.). Gêneros textuais: Reflexão e Ensino. Palmas e União da Vitória: Kaygangue, 2005.

KRESS, G.; VAN LEEUWEN, T. Colour as a semiotic mode: notes for a grammar of colour. Visual Communication, v. 1, n. 3, 2002, p. 343-369.

Reading Images: a grammar of visual designer. London: Routledge, 1996.

KRESS, G. Multimodality: challenges to thinking about language. TESOL Quarterly v. 34, n. 2, 2000, pp. 337-340. Disponível em: <http://www.jstor.org/stable/3587959>. Acesso em: 24 set 2017.

Multimodal Discourse: the modes and media of contemporary communication. London: Oxford University Press, 2001.

LIMA, B.A. de. Caminho Suave. São Paulo: Editora Caminho Suave, 2015.

MAYER, R. E. Multimedia learning. Cambridge: Cambridge University, 2009.

PINHEIRO, P. A. Sobre o Manifesto "a Pedagogy of multiliteracies: designing social futures" - 20 anos depois. Trab. linguist. Apl, v. 55 n. 2, Campinas, 2016. Disponível em: < http://www.scielo.br/pdf/tla/v55n2/0103-1813-tla-55-02-00525.pdf> Acesso em: 02 out 2017. 
ROJO, R. Letramentos múltiplos, escola e inclusão social. São Paulo: Parábola Editorial, 2009.

. Pedagogia dos multiletramentos: diversidade cultural e de linguagens na escola. In: ROJO, R; ALMEIDA, E de M. (orgs.). Multiletramentos na escola. São Paulo: Parábola Editorial, 2012.

SIMPSON, J. (Ed.). The Routledge handbook of applied linguistics. New York: Routledge, 2011.

SOARES, M. Letramento: um tema em três gêneros. 2. ed. Belo Horizonte: Autêntica, 2012. VAN LEEUWEN, T. Multimodality. In: SIMPSON, J. (Ed.). The Routledge handbook of applied linguistics. New York: Routledge, 2011. p. 668-682. 